\title{
A study of influence of material properties on magnetic flux density induced in magneto rheological damper through finite element analysis
}

\author{
T. M. Gurubasavaraju ${ }^{1 *}$,Kumar Hemantha ${ }^{1}$ and Mahalingam Arun ${ }^{1}$ \\ ${ }^{1}$ Department of Mechanical Engineering, National Institute of Technology Karnataka, Surathkal, \\ India.
}

\begin{abstract}
Magnetorheological fluids are smart materials, which are responsive to the external stimulus and changes their rheological properties. The damper performance (damping force) is dependent on the magnetic flux density induced at the annular gap. Magnetic flux density developed at fluid flow gap of MR damper due to external applied current is also dependent on materials properties of components of MR damper (such as piston head, outer cylinder and piston rod). The present paper discus about the influence of different materials selected for components of the MR damper on magnetic effect using magnetostatic analysis. Different materials such as magnetic and low carbon steels are considered for piston head of the MR damper and magnetic flux density induced at fluid flow gap (filled with MR fluid) is computed for different DC current applied to the electromagnetic coil. Developed magnetic flux is used for calculating the damper force using analytical method for each case. The low carbon steel has higher magnetic permeability hence maximum magnetic flux could pass through the piston head, which leads to higher value of magnetic effect induction at the annular gap. From the analysis results it is observed that the magnetic steel and low carbon steel piston head provided maximum magnetic flux density. Eventually the higher damping force can be observed for same case.
\end{abstract}

\section{Introduction}

The magnetorheological dampers are smart devices, whose damping force can be varied upon a change in the current. The MR damper force is highly influenced by the amount of magnetic flux induced in the MR damper due to the current supplied to the electromagnetic coil. Many investigations on computing the damping force through different approach have been investigated in the literature. Nguyen et al. (2008) [1] developed a novel optimization method based on finite element analysis to compute the optimal parameters. Zhang et al. (2006) [2] developed a method to design the MR damper constructed on the magnetic design through FE analysis. The MR damper design was experimentally verified. Tu et al.

* Corresponding author: gbrajtm@gmail.com 
(2007) [3] conducted FE analysis using MR damper axisymmetric model in ANSYS to calculate the total magnetic field developed in the MR damper. Guo et al. (2003) [4] carried out optimal design of MR valve though FE analysis and this analysis was further coupled with a fluid plastic model to estimate the MR valve performance. Hu et al. (2015) [5] considered double electromagnetic coil MR damper for the FE based optimization to identify optimal geometric variables. Also, the effect of different piston configurations such as geometric features, shape and size on the damping force was investigated. Paul et al. (2014) [6] presented an investigation on characteristics of MR fluid and its effect on the MR damper through commercially available FE software and the analysis results obtained were validated with the experimental results. Gurubasavaraju et al. (2017) [7] evaluated the optimal geometric parameters of the monotube MR damper operating under shear mode through response surface and multi objective genetic algorithm optimisation technique. In the present paper, the variation in the damper performance due to usage of different materials for the piston head is investigated.

\section{Finite Element Analyses}

The FE analysis is employed particularly for calculating induced magnetic field in the flow gap of MR damper for various currents. The magnetostatic module in ANSYS Workbench is employed for the analysis. The dynamic characteristics of a damper is dependent on the total magnetic flux developed in the damper. There are still other parameters, which are having impact on generation the magnetic flux, such as materials used for the MR damper components, geometric dimensions etc. The materials used for piston head in the present $\mathrm{FE}$ analysis are given in table 1. The CAD model of the MR damper and boundary conditions for the analysis are depicted in figure 1.

There are totally 4330 tetrahedron elements generated in the meshed model. The electromagnetic coil incorporated in the piston head consists of 600 turns of copper wire. There are few assumptions are made in the analysis such as zero flux leakage from the cylinder and flux lines are parallel to the center plane. DC current in the range of 0 to $1.0 \mathrm{~A}$ is supplied to the electromagnetic coil with an increment of $0.25 \mathrm{~A}$ to compute the magnetic field in the fluid flow gap for the respective current.

Table 1. MR damper model details.

\begin{tabular}{|c|c|c|}
\hline SI.No & Model & Piston head material \\
\hline 1 & 'Model 1' & M36 Steel \\
\hline 2 & 'Model 2' & SA1020 Steel \\
\hline 3 & 'Model 3' & SST430 Steel \\
\hline
\end{tabular}

The materials chosen for different components of MR damper are shown the table 2 . The material properties are also an important parameter, which influences the results of the analysis. In this study, all components of MR damper materials are kept unaltered except the piston head material. The material which is having high magnetic permeability could yield the higher value of magnetic flux. The change in the rheological properties of the MR fluid on application of magnetic flux is realized by calculating the shear yield stress. The magnetic field obtained from FEA is further used for estimating the field dependent yield stress using the equation 1 (Han et al. (2014) [8]). Calculated yield stress further employed to evaluate the damping force.

$$
\tau_{y}(p a)=39.71 B_{0}^{4}-132.45 B_{0}^{3}+119.2 B_{0}^{2}+10.31 B_{0}+0.11
$$

where, $t_{\mathrm{y}}$ is field dependent yield stress and $\mathrm{B}_{0}$ is magnetic flux density $(\mathrm{T})$. 

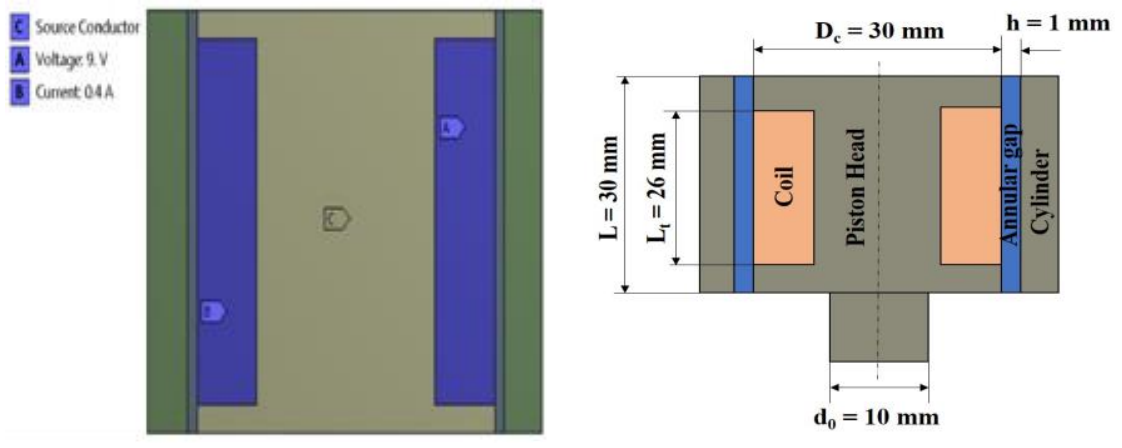

Fig. 1. MR Damper model dimensions

Table 1. MR damper model details.

\begin{tabular}{|c|c|c|c|}
\hline SI.No & Part name & Material & Relative Permeability \\
\hline 1 & Piston Head & SA1020, M36, SST430 & B-H Curve (Figure 2b, 2c, 2d) \\
\hline 2 & Coil & Copper wire & 1 \\
\hline 3 & Cylinder & Stainless Steel & 2000 \\
\hline
\end{tabular}

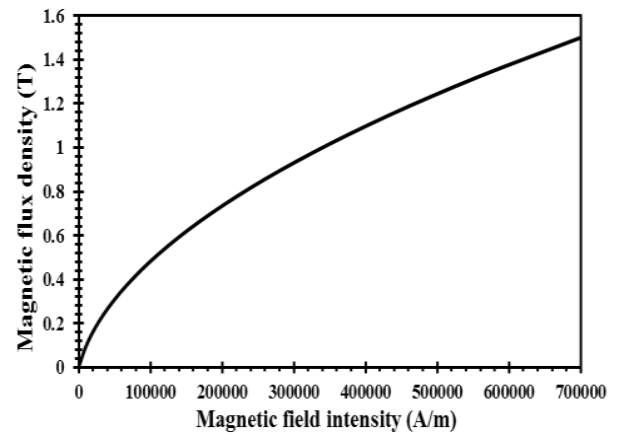

(a)

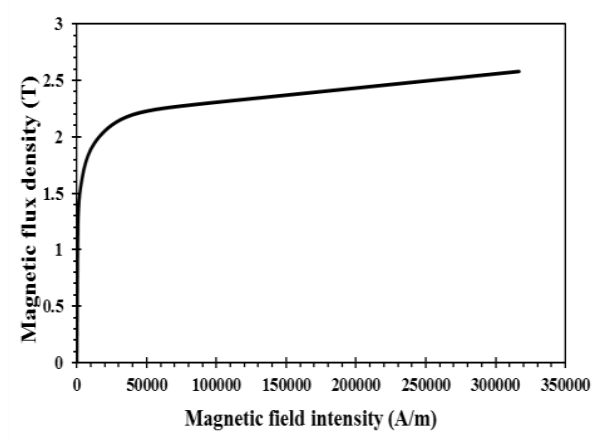

(c)

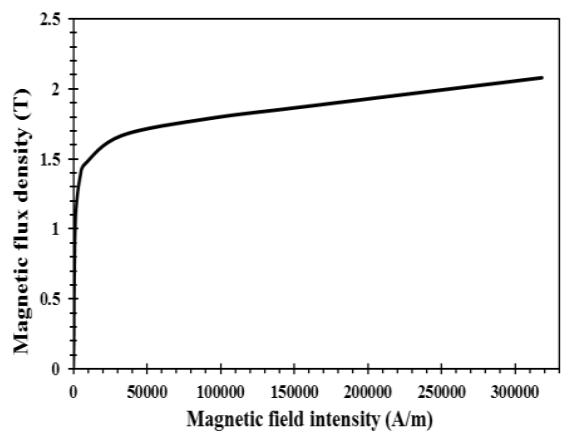

(b)

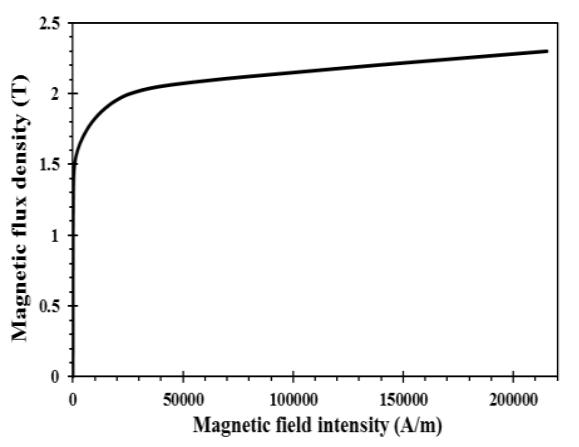

(d)

Fig. 2. B-H Curve of (a) MRF-132 DG (Lord Co.) [9] (b) SA1020 (c) SST430 and (d) M36 


\subsection{Results of FE analysis}

The contour plots of magnetic flux density computed from the magnetostatic analysis are shown in figure 3. The variation of magnetic flux at the fluid flow gap is extracted and plotted with respect to the fluid flow gap length as shown in the figure 4. It can be observed from the results that; the magnetic flux increases with increase in DC current. The increase in the magnetic flux is almost linear up to $0.3 \mathrm{~A}$ and further it tends to saturation level with increase in current as depicted in figure 4 (d).

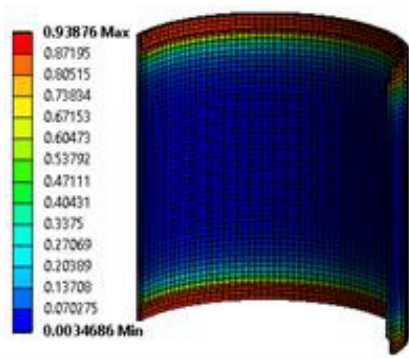

(a)

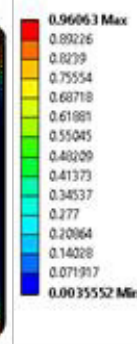

on1947 $0035552 \mathrm{M}$

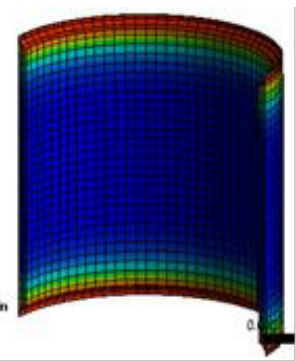
(b)

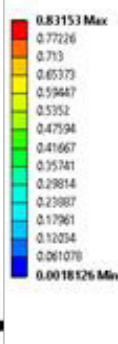

ation $001828 \mathrm{M}$

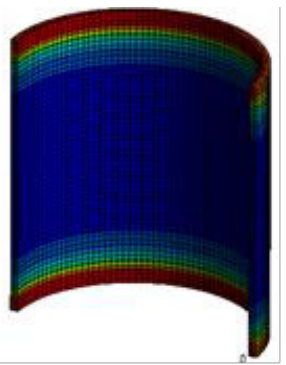

(c)

Fig. 3. Contour plots of magnetic flux density induced at the fluid flow gap of (a) 'Model 1', (b)

'Model 2' and (c) 'Model 3' MR dampers.

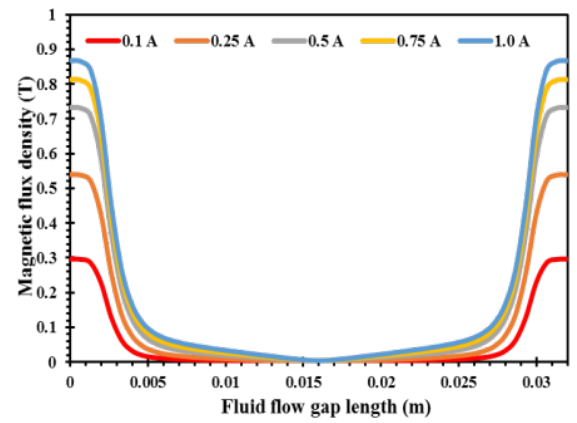

(a)

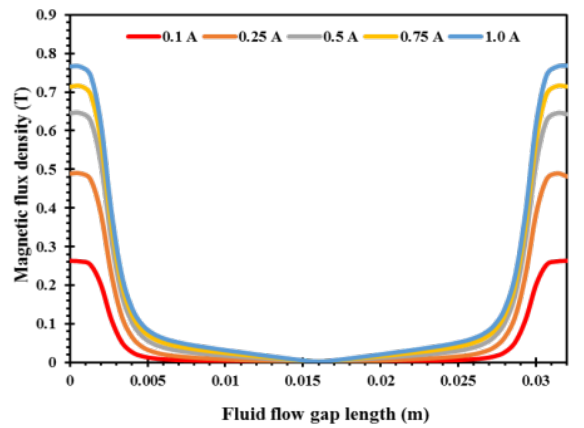

(c)

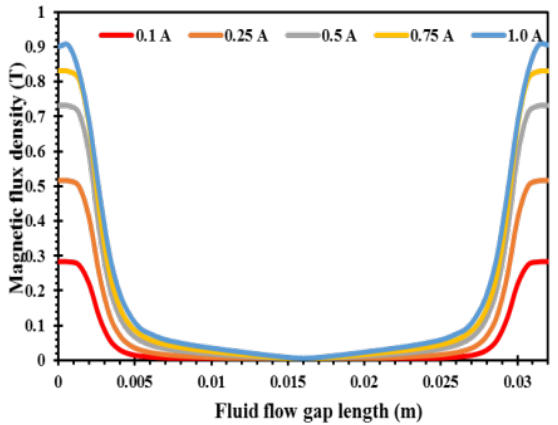

(b)

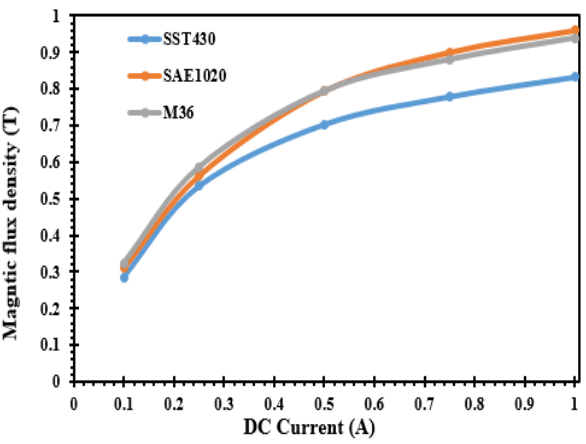

(d)

Fig. 4. Magnetic flux density at fluid flow gap (a) 'Model 1' M36 (b) 'Model 2' SA1020 (c) 'Model 3' SST 430 and (d) Maximum magnetic flux density. 
From the figure 4, it can be observed that the value of magnetic flux of 'model 1' and 'model 2' are nearly same and there is considerable difference between the model 3 and other models. The maximum magnetic flux is obtained for 'model 2' MR damper, because magnetic permeability of SA 1020 is significantly higher than the other two materials. Hence, maximum value of magnetic flux can be obtained by employing SA1020 material as the core for the electromagnetic coil.

\section{Estimation of damping force}

Equations (2) to (6) are used for computing the damping force of MR damper. The characteristic of MR damper is represented by force versus velocity plots. The damper force is the combined effect of force due to shear, viscous and frictional effect. The force due to shear stress is referred as controllable force and force due viscosity and friction forces are referred as uncontrollable forces. (Xu et al. (2013) [10] and Ronge et al. (2011) [11]). Figure 5 shows schematic diagram of MR damper.

$$
\begin{aligned}
& F=\left(2.07+\frac{12 Q \mu}{12 Q \mu+0.4 w h^{2} \tau_{y}}\right) \frac{\tau_{y} L A_{\eta}}{\hbar} \operatorname{sgn}(\dot{u})+\left(1+\frac{w g u}{2 Q}\right) \frac{12 \mu Q L A_{p}}{w h^{3}} \\
& w=\pi\left(\frac{h}{2}+D+\frac{h}{2}\right) \\
& A_{p}=\frac{\pi\left(D^{2}-d_{0}^{2}\right)}{4} \\
& \mu=0.0006 \hat{\gamma}^{-0.6091} \\
& \tilde{\gamma}=\frac{v}{2 * \hat{h}}
\end{aligned}
$$

where,

$\dot{\gamma}=$ Shear rate, $\mathrm{L}=$ Effective pole length $(\mathrm{mm}), \mathrm{w}=$ Circumference of fluid flow gap $(\mathrm{mm})$, $\mathrm{D}=$ Piston head diameter $(\mathrm{mm}), \mathrm{h}=$ Fluid flow gap $(\mathrm{mm}), \mu=$ Viscosity $(\mathrm{Pa}-\mathrm{s}), \mathrm{t}_{\mathrm{y}}=$ Shear stress $(\mathrm{Pa}), \mathrm{d}_{0}=$ Piston rod diameter $(\mathrm{mm}), \mathrm{Q}=$ Flow rate $\left(\mathrm{mm}^{3} / \mathrm{s}\right), \mathrm{v}=$ Velocity $(\mathrm{mm} / \mathrm{s})$, $\mathrm{D}_{\mathrm{c}}=$ Cylinder diameter $(\mathrm{mm})$ and $\mathrm{A}_{\mathrm{p}}=$ Effective piston head area $\left(\mathrm{mm}^{2}\right)$

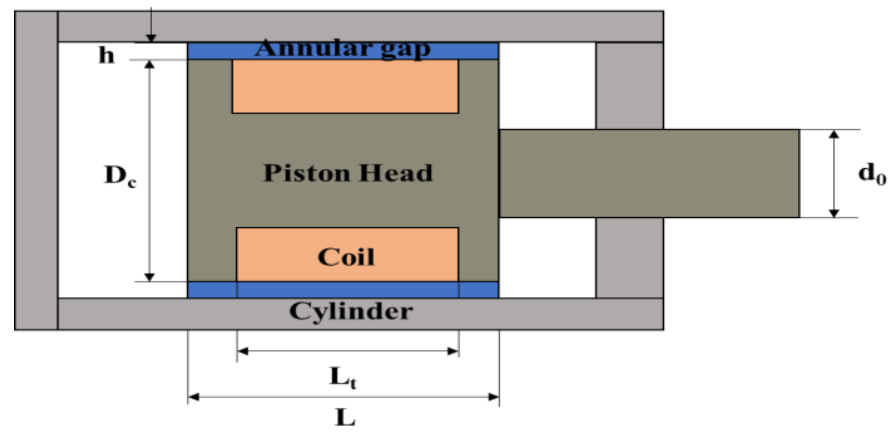

Fig. 5. Schematic diagram of MR damper

The force induced in the MR damper is calculated for $0.1 \mathrm{~A}, 0.25 \mathrm{~A}, 0.5 \mathrm{~A}, 0.75 \mathrm{~A}$ and $1.0 \mathrm{~A}$ current and for a piston velocity of $10 \mathrm{~mm} / \mathrm{s}$. Figure 6 illustrates the force versus velocity curves of three models. The maximum force developed in damper increases with current supplied to electromagnetic coil in each model of MR damper. The change in the damping force is significant due to increment in current. The maximum force obtained in 
case of 'model 1', 'model 2' and 'model 3' are 209N, $210 \mathrm{~N}$ and $192 \mathrm{~N}$ respectively for constant current of 1.0 A. Since magnetic flux density have direct influence on the damping force of MR damper, the damper which has higher value of magnetic flux yields higher damping force.

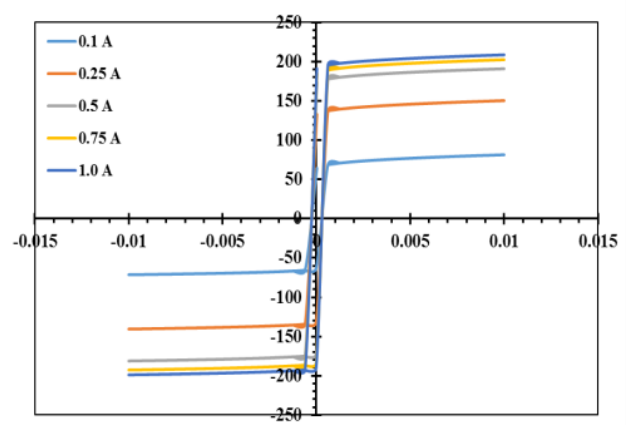

(a)

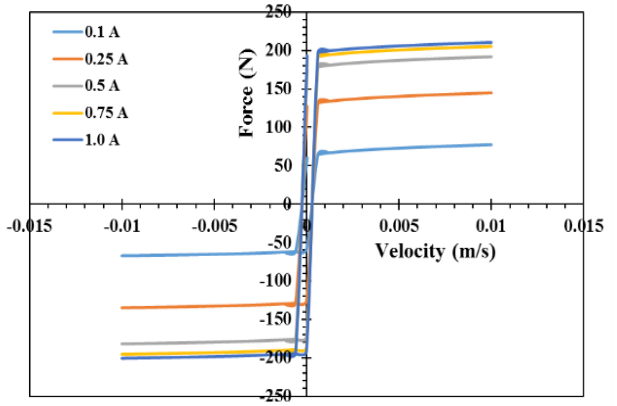

(b)

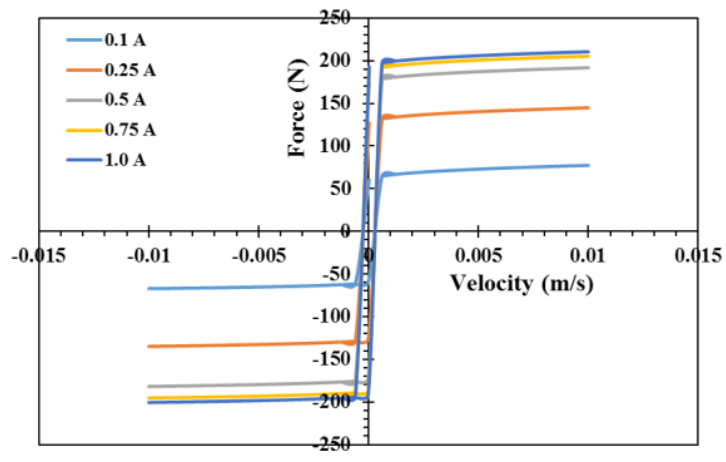

(c)

Fig. 5. Force versus velocity of MR damper for (a) 'Model 1' (M36) (b) 'Model 2' (SA1020) and (c) 'Model 3' (SST 430).

\section{Conclusions}

In the present work, piston head material influence on the damping force of the MR damper was evaluated through computational and analytical methods. Three different materials were considered as the material for piston head viz., M36, SA1020 and SST 430. Initially, the magnetic flux induced in the annular gap for different DC current input were computed through finite element analysis using ANSYS. The obtained magnetic flux was used for obtaining damper force versus velocity behavior through analytical method. It was observed that; higher value of magnetic flux can be obtained by employing SA1020 as the piston head material compared to other two materials. Consequently, the 'model 2' damper with SA1020 as the piston head material resulted in maximum damping force.

\section{Acknowledgment}

The authors acknowledge IMPRINT project No. IMPRINT/2016/7330 titled with "Development of Cost Effective Magneto-Rheological (MR) Fluid Damper in Two wheelers and Four Wheelers Automobile to Improve Ride Comfort and Stability" funded 
by Ministry of Human Resource Development and Ministry of Road Transfer and Highways, Govt. of India.

\section{References}

1. Q. H. Nguyen, S. B. Choi, and N. M. Wereley, “Optimal design of magnetorheological valves via a finite element method considering control energy and a time constant," Smart Mater. Struct, 17(2), 025024, 2008.

2. H. H. Zhang, C. R. Liao, W. M. Chen, and S. L. Huang, "A magnetic design method of MR fluid dampers and FEM analysis on magnetic saturation”, J. Ingt Mtrl. Sys and Struct, 17(8-9), 813-818, (2006).

3. S. H. Tu, and W. S. Jeng, "Finite Element Analysis of a Magnetorheological Fluid Damper." CSME conference, (2007).

4. N. Q. Guo, H. Du, and W. H. Li, "Finite element analysis and simulation evaluation of a magnetorheological valve,” Int. J. adv. Manuf. Tech, 21(6), 438-445, (2003).

5. G. Hu, Z. Xie, W. Li, "Optimal design of a double coil magnetorheological fluid damper with various piston profiles" In11th World Congress on Struct. Multidis. Opt., pp. 1-6 Jun (2015).

6. D. Paul, A. Moinuddin, M.M.N. Islam, M. D. Paul, M. A. Moinuddin, and M. M. N. Islam, "Finite Element Analysis and Simulation of a Magneto-Rheological Damper," International Journal, 1, 12-19, (2014).

7. T. M. Gurubasavaraju, H. Kumar, and M. Arun, "Optimisation of monotube magnetorheological damper under shear mode,” J. Braz. Soc. Mech. Sci. Eng, 39(6), 2225-2240, (2017).

8. S. B. Choi, Y. M. Han, "Magnetorheological fluid technology: applications in vehicle systems. CRC Press, (2014).

9. http://www.lordmrstore.com/_literature_231215/Data_Sheet_-_MRF132DG_Magneto-Rheological_Fluid.

10. Z.D. Xu, L.F. Sha, X.C. Zhang, H.H. Ye, "Design, performance test and analysis on magnetorheological damper for earthquake mitigation”. Sruct. Control. Hlth, 20, 6, pp. 956-70, Jun (2013).

11. B.P. Ronge, S.R. Kajale, and P.M. Pawar, "Theoretical and Experimental Analysis of MR Fluid Dampers,” (LAP Lambert Academic publishing, 2011). 